\title{
Commentary: The way to a patient's heart is through the stomach
}

\author{
Subhasis Chatterjee, MD
}

\footnotetext{
From the Divisions of General and Cardiothoracic Surgery, Michael E. DeBakey Department of Surgery, Baylor College Medicine, Houston, Tex; and the Department of Cardiovascular Surgery, Texas Heart Institute, Houston, Tex.

Disclosures: Author has nothing to disclose with regard to commercial support.

Received for publication May 17, 2019; accepted for publication May 21, 2019; available ahead of print June 7, 2019.

Address for reprints: Subhasis Chatterjee, MD, Michael E. DeBakey Department of Surgery, Baylor College of Medicine, One Baylor Plaza, MS: BCM 390, Houston, TX 77030-3411 (E-mail: subhasis.chatterjee@ bcm.edu). J Thorac Cardiovasc Surg 2019;158:1111-2 $0022-5223 / \$ 36.00$

Copyright (C) 2019 by The American Association for Thoracic Surgery https://doi.org/10.1016/j.jtcvs.2019.05.020
}

Stoppe and colleagues ${ }^{1}$ are recognized for their contributions in nutrition, and they provide a thoughtful reminder of the vital role of nutrition support in patients undergoing cardiac surgery (CS). They are to be commended for demanding that perioperative nutrition receive more than lip service and that we do nutrition support better. The authors provide context for significant investigations in nutrition support that have produced insights to help us think about fundamental questions: Why? In whom? When? How? How much?

\section{WHY?}

Patients requiring more than 3 days of intensive care unit care after CS are at high risk of receiving inadequate nutrition therapy. ${ }^{2}$ In theory, optimal postoperative nutrition maintains gut integrity and promotes wound healing, thereby reducing the risk of infection. Patients undergoing CS have been shown to receive less nutrition than any other medical or surgical cohort of patients in intensive care units. ${ }^{3}$ Although it is intuitive that patients with malnutrition have worse outcomes after CS, no adequately powered trial has yet shown whether early nutrition therapy improves outcomes in patients undergoing CS who are considered high risk for malnutrition. Perhaps nutritional status is more of a thermostat indicative of the general severity of illness rather than a discrete deficiency that can be easily corrected, such as a low potassium or magnesium level. The key is to identify those patients who could benefit the most from earlier nutrition intervention.

\section{IN WHOM?}

Patients undergoing CS are high-risk, and multiple available online calculators such as the Nutrition Risk in the Critically Ill Score can identify those who are vulnerable to malnutrition. ${ }^{4}$ The validation study of the CS Johns Hopkins Hospital Nutrition Support Score showed that 9\% of patients undergoing CS need nutrition support

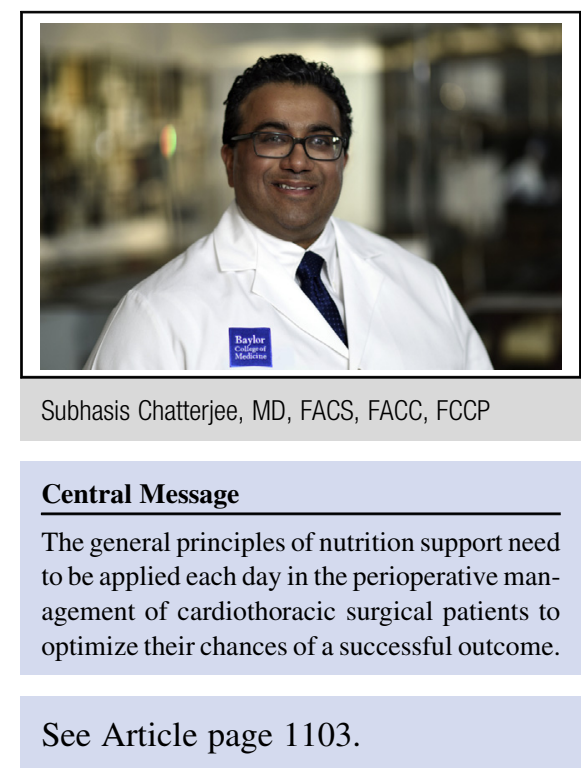

postoperatively. ${ }^{5}$ Supplementing standard nutritional formulas - modified by the addition of arginine, omega- 3 fatty acids, and glutamine, among others - may enhance immune response by modulating inflammatory markers or augmenting protein synthesis (immunonutrition). ${ }^{6}$ Indeed, recent guidelines for enhanced recovery after CS recommend preoperative albumin-level testing and correcting nutritional deficits when feasible. ${ }^{7}$ Although assessing patients' current nutritional status helps to identify those who are already undernourished, it does not identify patients who are at a precritical level of malnutrition and are therefore at elevated risk from CS.

\section{WHEN?}

The biggest barriers to starting nutrition support may be human factors. It may not be until 3 to 4 days after surgery, when prolonged ventilation appears likely, that enteral access is achieved and trickle feedings are started, so that it takes almost a week to achieve goal nutrition. Intuitively, initiating nutrition support earlier would seem to be beneficial; however, a study of more than 4600 patients in intensive care units showed the opposite: Initiating parenteral nutrition (PN) later actually resulted in faster recovery and fewer infections than initiating PN early.,

\section{HOW?}

Perhaps the most thought-provoking message of Stoppe and colleagues' report ${ }^{1}$ is that our inclination to "always 
use the gut" leads to most patients receiving enteral nutrition (EN) alone instead of EN plus supplemental PN, leading us to ignore the obvious benefits of $\mathrm{EN}+\mathrm{PN}^{2}$ For a variety of reasons-low cardiac output, vasoactive medications, fluid overload-patients after CS may not have optimal absorption of enteral contents. The greatest source of reluctance to use PN more liberally after CS may be concern about increased risk of infection, particularly an understandable reluctance to avoid bacteremia in patients who have received valve prostheses, aortic grafts, or mechanical assist devices in addition to chest tubes, pulmonary artery catheters, a dialysis line, and other potential vectors for infection. It is reassuring that recent trials have not shown an elevated risk of infection in EN + PN cohorts; however, we still await similar evidence that $\mathrm{EN}+\mathrm{PN}$ improves clinical outcomes without increasing infection risk after CS.

\section{HOW MUCH?}

Given the prevalence of underfeeding, an obvious strategy would be to augment the number of calories delivered. However, the landmark Augmented Versus Routine Approach to Giving Energy Trial (TARGET) ${ }^{9}$ showed that delivering more calories with an energy-dense nutrition product did not improve 90-day survival or other secondary outcomes in mechanically ventilated intensive care unit patients. Stoppe and colleagues ${ }^{1}$ rightly point out that protein underfeeding (patients received about half the recommended amount) could have influenced the results. Finally, Stoppe and colleagues ${ }^{1}$ note that "permissive underfeeding" (1000 kcal/d) or "trophic feeding" (400 kcal/d) have produced disparate results in critically ill patients.
The thoughtful commentary Stoppe and colleagues ${ }^{1}$ offer on nutrition support informs us that much investigation will be needed to produce meaningful improvements in post-CS nutrition outcomes. We still await trials in patients undergoing CS that will demonstrate an improvement in outcomes with various nutrition interventions. In the meantime, the general principles need to be applied each day in the perioperative management of our patients.

\section{References}

1. Stoppe C, Whitlock R, Arora RC, Heyland D. Nutrition support in cardiac surgery patients: be calm and feed on! J Thorac Cardiovasc Surg. 2019; 158:1103-8.

2. Rahman A, Agarwala R, Martin C, Nagpal D, Teitelbaum M, Heyland DK. Nutrition therapy in critically ill patients following cardiac surgery: defining and improving practice. JPEN J Parenter Enteral Nutr. 2017;41:1188-94.

3. Drover JW, Cahill NE, Kutsogiannis J, Pagliarello G, Wischmeyer P, Wang M, et al. Nutrition therapy for the critically ill surgical patient: we need to do better! JPEN J Parenter Enteral Nutr. 2010;34:644-52.

4. Hill A, Nesterova E, Lomivorotov V, Efremov S, Goetzenich A, Benstoem C, et al. Current evidence about nutrition support in cardiac surgery patients-what do we know? Nutrients. 2018;10.

5. Ohkuma RE, Crawford TC, Brown PM, Grimm JC, Magruder JT, Kilic A, et al. A novel risk score to predict the need for nutrition support after cardiac surgery. Ann Thorac Surg. 2017;104:1306-12.

6. Moya P, Soriano-Irigaray L, Ramirez JM, Garcea A, Blasco O, Blanco FJ, et al. Perioperative standard oral nutrition supplements versus immunonutrition in patients undergoing colorectal resection in an enhanced recovery (ERAS) protocol: a multicenter randomized clinical trial (SONVI study). Medicine (Baltimore). 2016;95:e3704.

7. Engelman DT, Ben Ali W, Williams JB, Perrault LP, Reddy VS, Arora RC, et al. Guidelines for perioperative care in cardiac surgery: enhanced recovery after surgery society recommendations. JAMA Surg. May 4, 2019 [Epub ahead of print].

8. Casaer MP, Mesotten D, Hermans G, Wouters PJ, Schetz M, Meyfroidt G, et al. Early versus late parenteral nutrition in critically ill adults. N Engl J Med. 2011; 365:506-17.

9. Chapman M, Peake SL, Bellomo R, Davies A, Deane A, Horowitz M, et al. Energy-dense versus routine enteral nutrition in the critically ill. $N$ Engl J Med. 2018;379:1823-34. 